\title{
Cudrania tricuspidata leaf extracts and its components, chlorogenic acid, kaempferol, and quercetin, increase claudin 1 expression in human keratinocytes, enhancing intercellular tight junction capacity
}

\author{
Jaewhan Kim ${ }^{1 \dagger}$, Namjoon Cho ${ }^{1 \dagger}$, Eun-Mi Kim², Ki-Sun Park ${ }^{3}$, Yeon Woo Kang ${ }^{1}$, Joong Hyeon Nam4,
} Myoung Soo $\mathrm{Nam}^{4^{*}}$ and Kee K. Kim² ${ }^{2^{*}}$ (1)

\begin{abstract}
Dysfunction of tight junctions and their components can cause diverse skin diseases. Here, we investigated the expression of claudin 1, a major tight junction protein, and changes of tight junction capacity upon treatment of the extracts of Cudrania tricuspidata (C. tricuspidata) and its components, chlorogenic acid, kaempferol, and quercetin. The effects of ethanol extracts of $C$. tricuspidata (EECT) and water extracts of $C$. tricuspidata (WECT) on the viability of human keratinocyte $\mathrm{HaCaT}$ cells were assessed by cell proliferation assay. Quantitative reverse transcription polymerase chain reaction (qRT-PCR) was conducted to measure the expression of claudin 1 mRNA. The protein expression of claudin 1 was analyzed by western blot and its tight junctional distribution was observed with immunofluorescence microscopy analysis. The tight junction capacity was analyzed by dispase assay. Upon treatment of WECT to HaCaT cells, the mRNA and protein expressions of claudin 1 were increased. In addition, chlorogenic acid, kaempferol, and quercetin increased claudin 1 protein expression levels in a dose-dependent manner. WECT and these three compounds enhanced the tight junction capacity of HaCaT cells in dispase assay. WECT, and its components, such as chlorogenic acid, kaempferol, and quercetin, upregulates both mRNA and protein expressions of claudin 1, which leads to the enhancement of tight junction capacity. Thus, WECT could be a therapeutic approach for treating tight junction-disrupted conditions such as atopic dermatitis and psoriasis.
\end{abstract}

Keywords: Cudrania tricuspidata, Claudin 1, Tight junction, Chlorogenic acid, Kaempferol, Quercetin, Dispase assay

\section{Introduction}

Cudrania tricuspidata is a thorny, deciduous tree that is found throughout Japan, China, and Korea. The root bark and cortex of C. tricuspidata are used as crude Chinese

\footnotetext{
*Correspondence: namsoo@cnu.ac.kr; kimkk@cnu.ac.kr

†Jaewhan Kim and Namjoon Cho equally contributed to this study

2 Department of Predictive Toxicology, Korea Institute of Toxicology, Daejeon 34114, Republic of Korea

${ }^{4}$ Division of Animal Resource Science, Chungnam National University, Daejeon 34134, Republic of Korea

Full list of author information is available at the end of the article
}

drugs and ubiquitous traditional herbal remedies in East Asia [1]. Several studies found that root bark extracts induce apoptosis in human leukemia cells (HL-60 cells) and function as a hepatoprotective compound $[2,3]$. In addition, C. tricuspidata fruit was found to have anti-bacterial effects, and can suppress the development of atopic dermatitis $[4,5]$. Many studies have investigated the physiological and biochemical effects of $C$. tricuspidata in relation to its anti-inflammatory and anti-cancer activities [6-9]; however, the effects of C. tricuspidata on tight junction function are largely unknown. 
Tight junctions regulate the passage of water, ions, and molecules through the paracellular pathway. The permeability properties of tight junctions are variable among the many types of epithelia, and depend on specific requirements for transepithelial or transendothelial solute transport [10]. Several studies have identified more than 40 different proteins located within the tight junctions of epithelial, endothelial, and myelinated cells [11-15]. Among these proteins, members of the claudin family are directly involved in tight junction function. In particular, claudin 1 maintains the integrity of the paracellular barrier and regulates water homeostasis. Loss of claudin 1 in epithelial cells leads to a high susceptibility to external pathogens, and malfunctions of the skin barrier [1618]. Several studies have shown that skin diseases, such as atopic dermatitis, skin tumors, and dehydration, are caused by a loss of claudin 1 in tight junctions [19-21]. Interestingly, a recent study found that the symptoms of dinitrochlorobenzene (DNCB)-induced atopic dermatitis mice could be improved by increasing claudin 1 expression [22]. Thus, studying of the regulation of claudin 1 could be a considerably important factor for a better understanding on how to treat tight junction-mediated skin diseases.

In the present study, we investigated the effect of C. tricuspidata leaf extracts on tight junctions. We found that C. tricuspidata leaf extracts caused an increase in claudin 1 expression in $\mathrm{HaCaT}$ cells. In addition, the representative components of $C$. tricuspidata leaf extracts; chlorogenic acid, kaempferol, and quercetin also showed the similar activity on claudin 1 expression. Moreover, this increase in claudin 1 resulted in an enhancement of tight junction formation, where claudin 1 was predominantly located in the cellular membrane. We propose $C$. tricuspidata leaf extracts as a therapeutic treatment for tight junction-mediated skin diseases, due to their ability to increase claudin 1 expression.

\section{Materials and methods}

\section{Cudrania tricuspidata leaf extracts preparation and yield}

Cudrania tricuspidata leaves were gathered from farms in Gongju, Korea, in August 2017. Plant was botanically authenticated by Professor Dr. Myoung Soo Nam and deposited in the Division of Animal Resource Science, Chungnam National University, Daejeon, South Korea.

The leaves were washed with water and dried at room temperature. The dried leaves were ground into a fine powder, of which $10 \mathrm{~g}$ was mixed with $30 \mathrm{ml}$ distilled water or $90 \mathrm{ml}$ ethanol for $30 \mathrm{~min}$. Water extracts were centrifuged at $4000 \times g$ for $15 \mathrm{~min}$, followed by freeze-drying of the supernatant. Ethanol extracts were concentrated in vacuum evaporator at $55{ }^{\circ} \mathrm{C}$ until the ethanol was completely evaporated, followed by freezedrying. The yield of each extract was measured using the following equation: water extracts of $C$. tricuspidata leaf (WECT), 13.2 $\pm 0.125 \%$; ethanol extracts of C. tricuspidata leaf (EECT), $11.2 \pm 0.025 \%$.

$$
\text { Yield }(\%)=\frac{\text { Freeze-dried powder }(\mathrm{g})}{\text { Ground fine powder }(10 \mathrm{~g})} \times 100
$$

\section{Cell culture and chemicals}

Human keratinocytes ( $\mathrm{HaCaT}$ cells) were purchased from AddexBio (cat\# T0020001, CA, USA) and cultured in Dulbecco's Modified Eagle's Medium (DMEM) supplemented with 10\% heat-inactivated fetal bovine serum (Gibco, NY, USA), at $37^{\circ} \mathrm{C}$, in $5 \% \mathrm{CO}_{2}$. The main phenolic components of WECT; chlorogenic acid, kaempferol, and quercetin were purchased from Sigma-Aldrich (MO, USA). Chlorogenic acid, kaempferol, and quercetin were diluted in DMSO and treated to $\mathrm{HaCaT}$ cells with DMSO control.

\section{MTS assay}

$\mathrm{HaCaT}$ cells were cultured in 96-well plates and treated with WECT or EECT. After $24 \mathrm{~h}, 20 \mu \mathrm{l}$ MTS solution (Promega, WI, USA) was added and cells were incubated at $37^{\circ} \mathrm{C}$ for $1 \mathrm{~h}$. Using a microplate reader (Molecular Devices EMax Plus, CA, USA), absorbance was measured at $490 \mathrm{~nm}$. Cell viability was measured using the following equation:

$$
\begin{aligned}
\text { Cell viability }(\%)= & \left(\frac{\mathrm{A}_{\text {Experimental group }}-\mathrm{A}_{\text {Sample blank }}}{\mathrm{A}_{\text {control group }}}\right) \\
& \times 100
\end{aligned}
$$

\section{RNA preparation and quantitative RT-PCR analysis}

Total RNA was extracted from HaCaT cells, using a Hybrid- $^{\mathrm{TM}}$ Kit (GeneAll, Korea) according to the manufacturer's instructions. cDNA was synthesized using M-MLV reverse transcriptase (Promega, WI, USA) with random hexamers. To investigate changes in tight junction-related genes, primers were designed (Table 1) and quantitative real-time PCR (qRT-PCR) was performed. Briefly, synthesized cDNA, 2X Prime Q-master mix (Genet Bio, Korea), and $10 \mathrm{pmol} / \mu \mathrm{l}$ forward and reverse primers were mixed and applied to qRT-PCR using AriaMx (Agilent, USA). Temperature and cycle settings are as follow: $95^{\circ} \mathrm{C}, 20 \mathrm{~s} ; 58^{\circ} \mathrm{C}, 20 \mathrm{~s} ; 72{ }^{\circ} \mathrm{C}, 20 \mathrm{~s} ; 40$ cycles. $\beta$-Actin was used as internal standard. The specificity of each PCR product was confirmed by melting curve analysis.

Immunoblot and immunofluorescence microscopy analysis Cells were washed with phosphate-buffered saline (PBS) and lysed with Laemmli Sample Buffer (Bio-Rad, CA, USA). Total cell lysates were separated using SDS/ PAGE, transferred to a nitrocellulose membrane, and 
Table 1 Primers used for quantitative real-time PCR analysis of tight junction-related genes

\begin{tabular}{|c|c|c|c|c|}
\hline Gene & & Primer sequence $\left(5^{\prime}\right.$ to $\left.3^{\prime}\right)$ & Product size (bp) & $\begin{array}{l}\text { Annealing } \\
\text { temp. }\left({ }^{\circ} \mathrm{C}\right)\end{array}$ \\
\hline ZO-1 & $\begin{array}{l}F \\
R\end{array}$ & $\begin{array}{l}\text { AGA GCA CAG CAA TGG AGG AA } \\
\text { GAC GTT TCC CCA CTC TGA AA }\end{array}$ & 133 & 58 \\
\hline Occludin & $\begin{array}{l}\mathrm{F} \\
\mathrm{R}\end{array}$ & $\begin{array}{l}\text { TTT GTG GGA CAA GGA ACA CA } \\
\text { ATG CCA TGG GAC TGT CAA CT }\end{array}$ & 137 & 58 \\
\hline Claudin 1 & $\begin{array}{l}\mathrm{F} \\
\mathrm{R}\end{array}$ & $\begin{array}{l}\text { GCA GAT CCA GTG CAA AGT CT } \\
\text { CAT ACA CTT CAT GCC AAC GG }\end{array}$ & 136 & 58 \\
\hline Claudin 4 & $\begin{array}{l}\mathrm{F} \\
\mathrm{R}\end{array}$ & $\begin{array}{l}\text { CGC ATC AGG ACT GGC TTT AT } \\
\text { AGT TGA GGA CCT GGA AGG CT }\end{array}$ & 131 & 58 \\
\hline Claudin 6 & $\begin{array}{l}\mathrm{F} \\
\mathrm{R}\end{array}$ & $\begin{array}{l}\text { GGC CCT CTG AGT ACC CTA CC } \\
\text { GCA GGA GGC AGA AAC AAA AG }\end{array}$ & 136 & 58 \\
\hline Claudin 8 & $\begin{array}{l}F \\
R\end{array}$ & $\begin{array}{l}\text { GGC TGT TTC TTG GTG GTG TT } \\
\text { CAC GCA ATT CAT CCA CAG TC }\end{array}$ & 137 & 58 \\
\hline \multirow[t]{2}{*}{$\beta$-Actin } & $\mathrm{F}$ & TCA CCC ACA CTG TGC CCA TCT ACG A & 295 & 58 \\
\hline & $\mathrm{R}$ & CAG GGG AAC CGC TCA TTG CCA ATG G & & \\
\hline
\end{tabular}

blocked with $5 \%$ non-fat dry milk (Rockland, PA, USA). For immunofluorescence microscopy analysis, cells were cultured in 4-well chamber slides (Lab-Tek, NY, USA), fixed in $4 \%$ paraformaldehyde, and permeabilized with $0.5 \%$ Triton X-100. Then, cells were blocked with a $1 \%$ BSA and $5 \%$ goat serum solution. Antibodies for immunoblot and immunofluorescence analysis were as follows: anti-claudin 1 (Cell Signaling Technologies, MA, USA) and anti-tubulin alpha (Sigma-Aldrich, MO, USA).

\section{Dispase assay}

Confluent HaCaT cells were seeded in triplicate onto 12-well plates and treated with WECT, chlorogenic acid, kaempferol, and quercetin for $24 \mathrm{~h}$. The $\mathrm{HaCaT}$ cell monolayer was washed with PBS and treated with $1 \mathrm{ml}$ dispase solution (2.4 units/ml; Roche Diagnostics, Mannheim, Germany) for $1 \mathrm{~h}$. Cells were detached from the plate, physical stress was applied to split the cell layer into pieces, and fragments were manually counted.

\section{Statistical analysis}

Unpaired two-tailed Student's $t$-test was used for statistical analysis of data. $p$ value lower than 0.01 was considered statistically significant.

\section{Results}

\section{Effect of $C$. tricuspidata leaf extracts on cell viability}

Although several studies have shown that C. tricuspidata leaf extracts have biochemical and physiological activities, their effects on skin, such as in the maintenance of water homeostasis and protection against infection, are still unknown. Thus, we investigated the effects of $C$. tricuspidata leaf extracts on tight junctions, the most important component of the skin barrier. We evaluated cell viability using human epidermal keratinocytes ( $\mathrm{HaCaT}$ cells). $\mathrm{HaCaT}$ cells were treated with WECT or EECT for $24 \mathrm{~h}$, followed by an MTS assay. We found that WECT did not decrease cell viability to below $80 \%$, whereas cell viability was decreased to $51.6 \%$ at a $2.0 \mathrm{mg} / \mathrm{ml}$ concentration (Fig. 1). However, EECT strongly decreased cell viability at a $0.125 \mathrm{mg} /$ $\mathrm{ml}$ concentration, and at a concentration range of 0.25 to $2.0 \mathrm{mg} / \mathrm{ml}$ of EECT, cell viability was decreased to below $20 \%$.

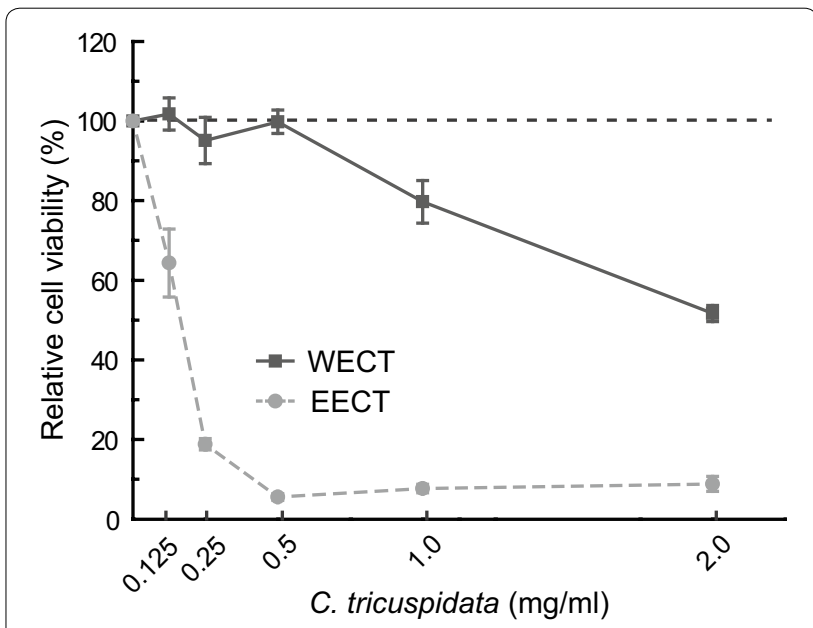

Fig. 1 Effect of C. tricuspidata leaf extracts on cell viability. HaCaT cells were treated with indicated concentrations of extracts for $24 \mathrm{~h}$, followed by an MTS assay 


\section{Claudin 1 mRNA expression is increased by WECT in a dose-dependent manner}

Tight junctions are composed of several transmembrane proteins, including claudin 1 and occludin. Here, we performed qRT-PCR to examine the regulatory effect of $C$. tricuspidata leaf extracts on the expression level of tight junction-related genes. As shown in Fig. 1, cell viability was not affected by treatment with $0.125,0.25$, or $0.5 \mathrm{mg} /$ $\mathrm{ml}$ WECT. When we treated HaCaT cells with the same concentrations of WECT for $24 \mathrm{~h}$, only claudin $1 \mathrm{mRNA}$ expression showed a dose-dependent increase (Fig. 2a). When $\mathrm{HaCaT}$ cells were treated with $0.125 \mathrm{mg} / \mathrm{ml} \mathrm{EECT}$, no significant changes in mRNA expression of tight junction-related genes were observed (Fig. 2b). Thus, we found that WECT upregulates the expression of claudin 1 in a dose-dependent manner.

\section{WECT increases tight-junctional claudin 1 expression and tight junction capacity}

We found that only WECT caused an increase in claudin 1 mRNA expression in HaCaT cells (Fig. 2a, b). Claudin 1 , the most important component of tight junctions, was significantly increased, meaning that treatment with WECT could enhance cell-cell adhesion in HaCaT cells. To investigate not only mRNA levels but also claudin 1 protein levels, we treated $\mathrm{HaCaT}$ cells with different concentrations of WECT, and assessed protein expression by western blot analysis. We found that claudin 1 protein was also increased in a dose-dependent manner, consistent with the increase in mRNA expression (Fig. 3a). Claudin 1 protein expression was increased 2.5 and 2.8 times following treatment with 0.5 and $1.0 \mathrm{mg} / \mathrm{ml} \mathrm{WECT}$, respectively, compared with control. Next, we investigated the subcellular localization of this increase in claudin 1 expression upon treatment with WECT. Using immunofluorescence microscopy analysis, we found that the increased claudin 1 was predominantly localized to tight junctions (Fig. 3b). This increase in claudin 1 means that the anchoring capacity of the tight junctions, which maintains cell-cell adhesion, is enhanced. To assess tight junction ability after treatment with WECT, we performed a dispase assay. WECT was added to $\mathrm{HaCaT}$ cells for $24 \mathrm{~h}$, then the dispase solution was added. After $1 \mathrm{~h}$, cells were detached from the bottom of the plate and
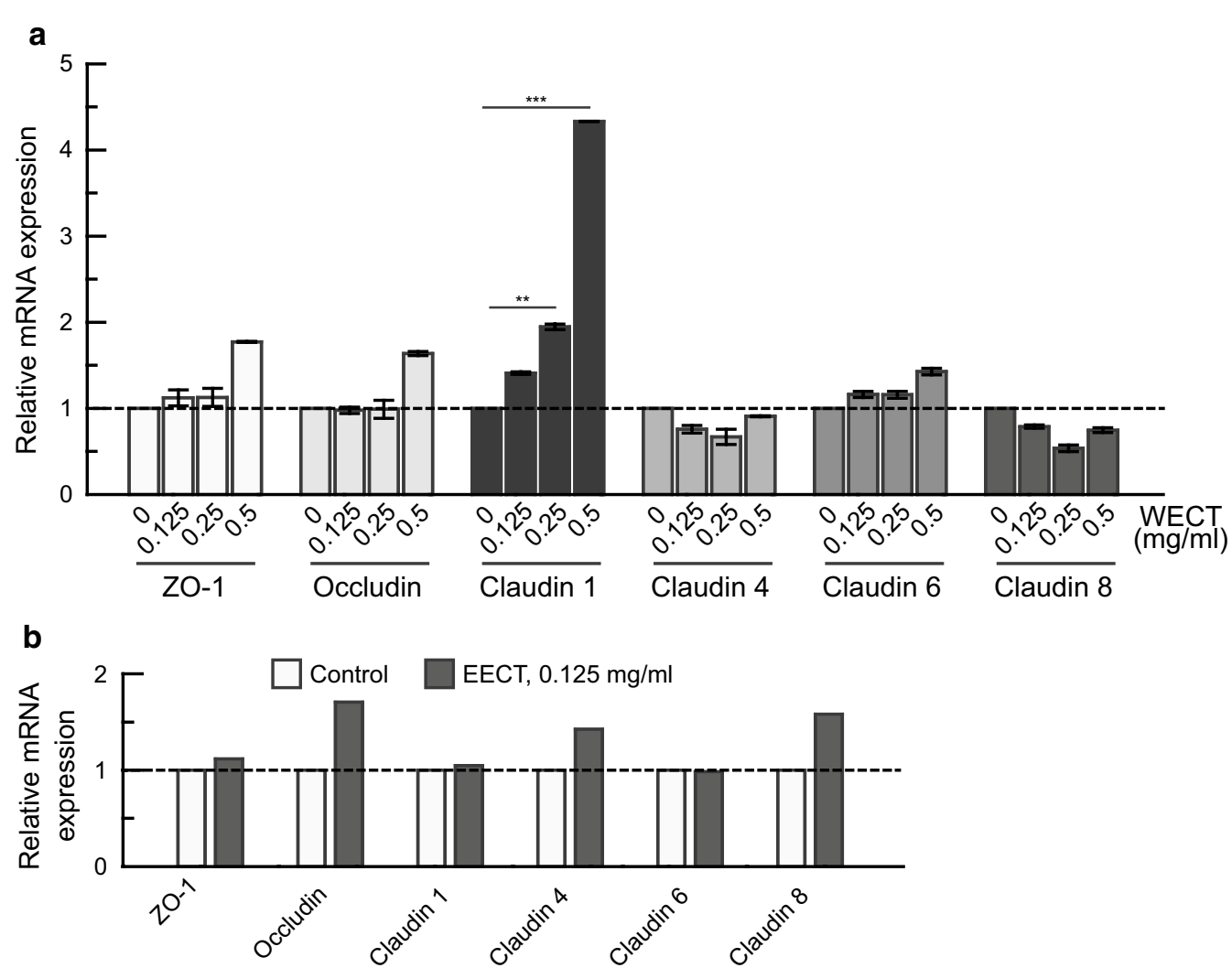

Fig. 2 Expression of tight junction-related genes. a HaCaT cells were treated with different concentrations of WECT for 24 h. Only claudin 1 mRNA was increased, in a dose-dependent manner. ${ }^{* *} p<0.01,{ }^{* * *} p<0.001$ (two-sided $t$-test, versus control) $\mathbf{b}$ Upon treatment with EECT, there were no significant changes in expression of tight junction-related genes 


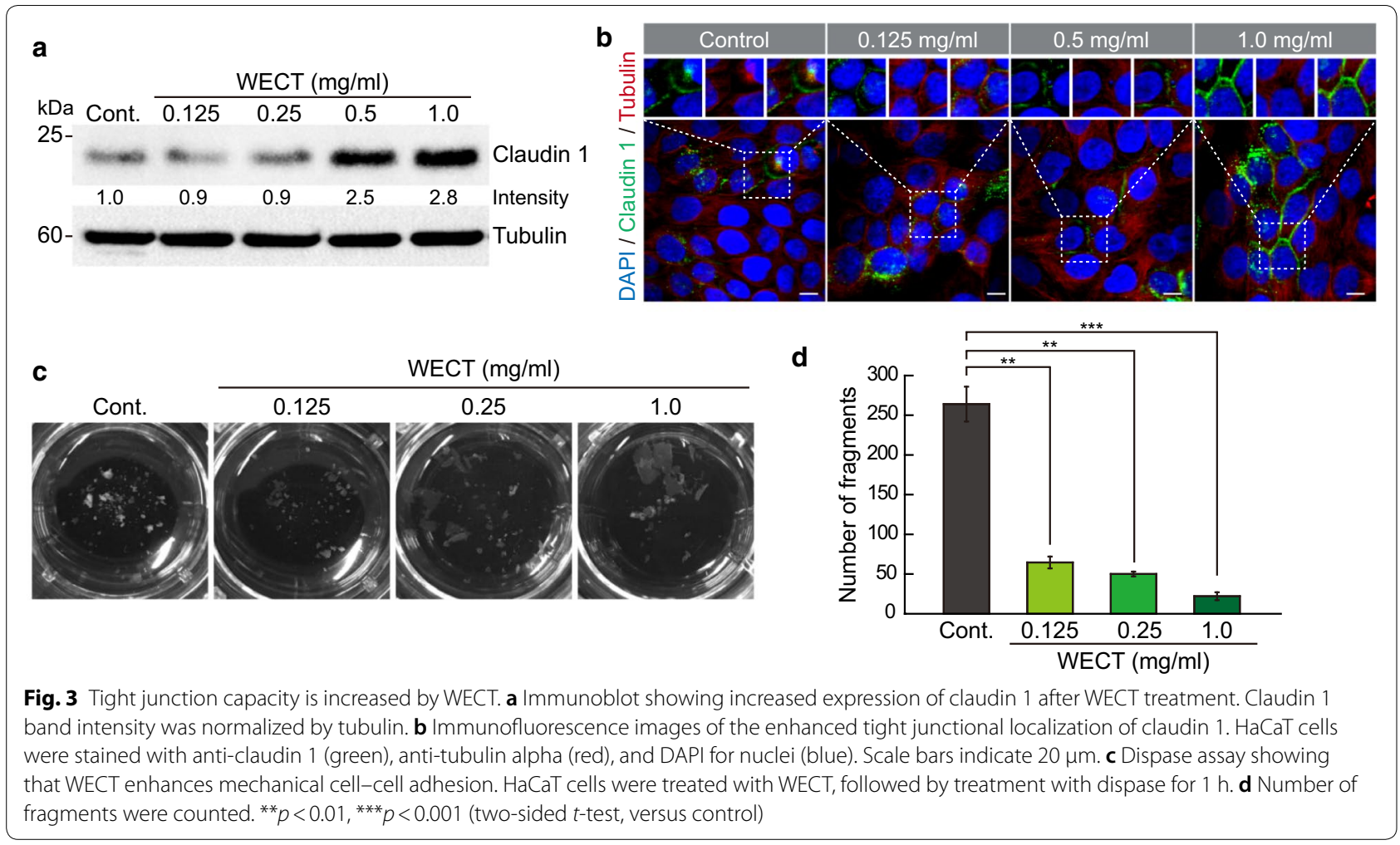

physical stress was applied to break the cell layer into pieces. Claudin 1, located at the cellular membrane as shown in Fig. 3b, was found to considerably enhance the tight junction capacity of $\mathrm{HaCaT}$ cells (Fig. 3c, d).

\section{The enhancement of tight junction capacity by the three major components of WECT}

Since it has been investigated that the components of $C$. tricuspidata water extract includes several bioactive phenolic compounds, we assessed whether those phenolic components are responsible for the increase of claudin 1 expression [23-25]. Among them, we treated chlorogenic acid, kaempferol, and quercetin to $\mathrm{HaCaT}$ cells, because they are the most abundance components and previously shown to have several bioactive effects [25]. The increase in claudin 1 protein expression was also shown in all of three components treated $\mathrm{HaCaT}$ cells (Fig. 4b). Furthermore, the increased claudin 1 was shown to be more localized in tight junctions, which resulted in the enhancement of tight junction ability (Fig. 4c, d).

Taken together, these data indicate that claudin 1 is increased at both the mRNA and protein level by WECT and its components, and that the increased claudin 1 is localized to the cellular membrane and enhances tight junction function in $\mathrm{HaCaT}$ cells. From our data, we demonstrate the potential possibility of WECT as an herbal therapeutic treatment for tight junction-related skin diseases such as atopic dermatitis, psoriasis, and erythroderma.

\section{Discussion}

Tight junctions mediate the selective movement of solutes across the epithelium, and form an intercellular barrier between adjacent epithelial cells. Claudin 1-deficient mice die within one day of birth from severe dehydration [26]. In addition, alterations in tight junctions and their related proteins in the skin lead to psoriasis, ichthyosis, and erythroderma. The increase in cell-to-cell binding capacity by modulating tight junction-related proteins, could be a double-edged sword. However, regarding the advantage of increasing tight junction capacity upon skin damage, we focused on the effects of $C$. tricuspidata leaf extracts on tight junctions and claudin 1 expression, as a potential therapeutic treatment of the disease showing decreased level of tight junction proteins. We found that extracts of $C$. tricuspidata the leaf showed high free radical scavenging activity, similar to resveratrol (data not shown). Free radicals are highly reactive oxygen species (ROS) associated with cell damage and senescence. Accordingly, the elimination of ROS by C. tricuspidata leaf extracts could prevent cellular damage and senescence of skin. Our data demonstrated high antioxidant effects of the C. tricuspidata leaf, indicating that the leaf 


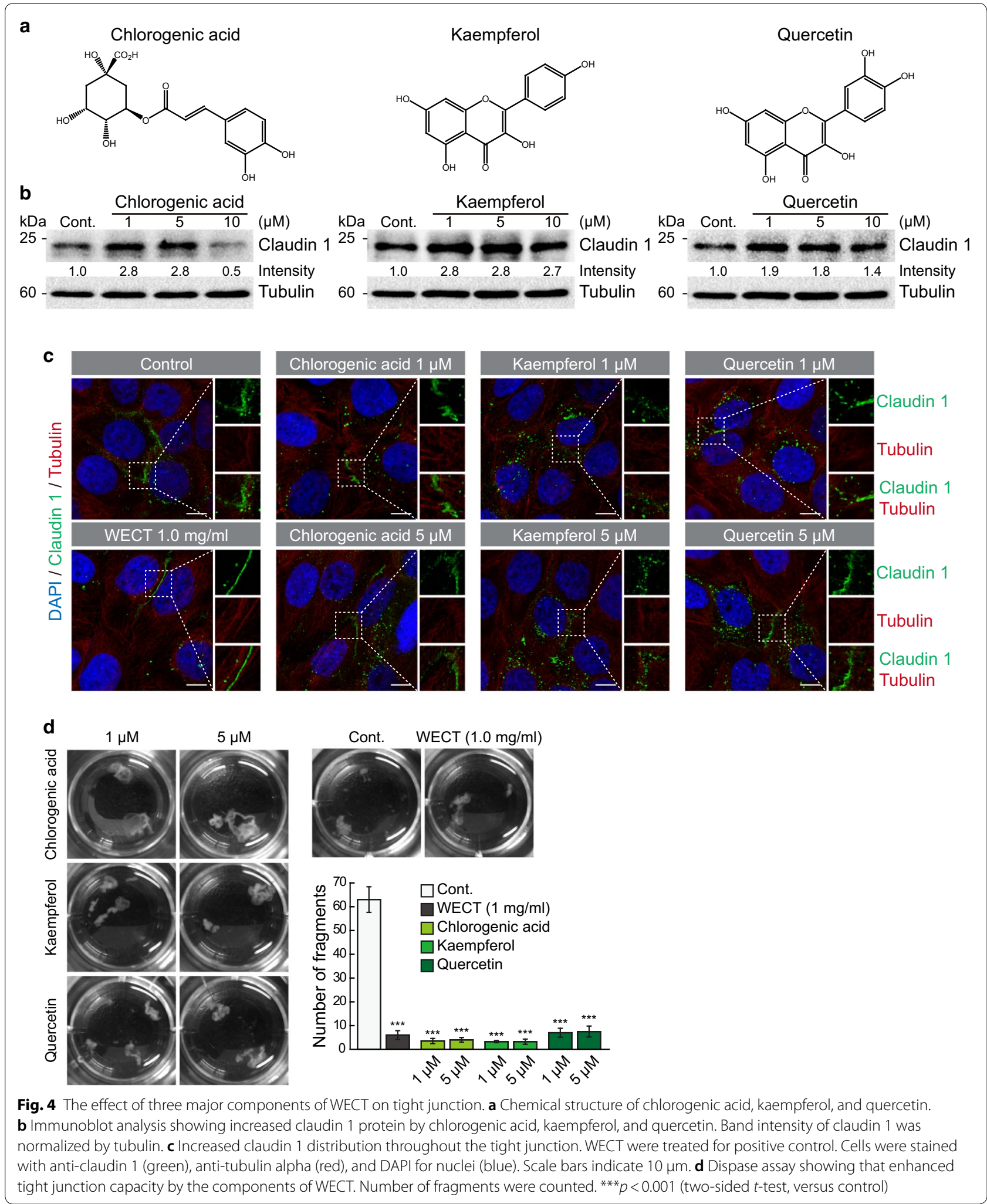


extracts can regulate the progression of ROS-mediated senescence or cellular damage. To investigate the biochemical and physiological effects of $C$. tricuspidata, we first examined the cytotoxicity of the extracts in $\mathrm{HaCaT}$ cells, in order to optimize the treatment concentration for further studies. WECT showed low cytotoxicity up to $0.5 \mathrm{mg} / \mathrm{ml}$, whereas EECT showed considerably higher cytotoxicity, even at the lowest concentration (Fig. 1). Although we equally adjusted the total volume of ethanol for each sample, it still significantly decreased cell viability. Thus, we speculated that the cytotoxic components of C. tricuspidata leaf, which have different solubilities in water and ethanol, might also have different effects on cell viability, causing the discrepancy between the two extracts. Based on our MTS data, we set the optimal concentrations to 0 to $0.5 \mathrm{mg} / \mathrm{ml} \mathrm{WECT}$, and 0 to $0.125 \mathrm{mg} /$ ml EECT.

The formation of tight junctions in the uppermost portion of the cellular membrane is established by the polarized insertion of diverse proteins, which are related to tight junctions. Thus, we proposed that if $C$. tricuspidata leaf extracts could upregulate the expression of those types of proteins, it could be a useful natural compound for treating tight junction-mediated diseases such as atopic dermatitis. Accordingly, we investigated changes in tight junction-related genes after treatment with C. tricuspidata leaf extracts. To our surprise, claudin 1 expression was gradually increased by WECT, whereas other genes were not affected (Fig. 2a). EECT was shown to have high cytotoxicity even at the lowest concentration (Fig. 1). Nevertheless, we evaluated its potential regulatory effects on tight junction-related genes, due to the fact that it could contain the same component as WECT that is responsible for the claudin 1 increase. However, the expression of tight junction-related genes was not significantly affected by treatment with EECT (Fig. 2b). In our previous study, we investigated the effect of the fruit extract of C. tricuspidata on tight junction-related genes. Therefore, effective ingredients and mechanism of action on the tight junction of the extract of C. tricuspidata by different parts are thought to be different. When EECT was treated for $48 \mathrm{~h}$, claudin 6 mRNA expression level was increased [27]. If the composition of the $C$. tricuspidata extract of the two sites is similar, this discrepancy may be caused by difference in treat time and if we treated EECT for longer time, we could see the same effect of EECT on claudin 6 expression level. Taken together, we speculate that the main components of $C$. tricuspidata leaf, which cause the increase in claudin 1 expression in $\mathrm{HaCaT}$ cells, are present only in WECT.

Given our observation that claudin 1 mRNA expression was increased in a dose-dependent manner, we speculated that $C$. tricuspidata leaf extracts would also upregulate its protein expression. Thus, we performed western blot analysis to investigate whether the level of claudin 1 protein also increased. As expected, claudin 1 expression was upregulated in $\mathrm{HaCaT}$ cells after WECT treatment, and expression levels were consistent with the qRT-PCR results (Fig. 3a). However, several studies have reported that claudin 1 is localized to the cytoplasm; therefore, we sought to determine the site of the increased claudin 1 expression after WECT treatment. Using immunofluorescence microscopy analysis, we found that the increased claudin 1 was predominantly located in the cellular membrane, indicating that claudin 1 -involved tight junction formation is strengthened by WECT (Fig. 3b-d). Natural material extract like WECT consists of many compounds. Thus, it was needed to identify the components of WECT that is responsible for the increase in claudin 1 expression. The major components of WECT and EECT were previously well studied and their functions were involved in anti-inflammation, cancer treatment, and several bioactivities [23, 28, 29]. Even though, the three active compounds are contained differently in WECT or EECT [23-25], the purpose of our study is to suggest the activity of the extracts on tight junction which could be applied to functional food and treatment of tight junction-mediated diseases. Thus, we chose only WECT, due to its low cytotoxicity. As shown in Fig. $4 \mathrm{~b}$ and c, all of those well-known components of WECT, chlorogenic acid, kaempferol, and quercetin increased claudin 1 expression, even when treated at the lowest concentration. Same with the effect of WECT on tight junction capacity, the major three components also enhanced tight junction ability (Fig. 4d). However, it has been demonstrated that component of C. tricuspidata, oxyresveratrol, has tyrosinase inhibition activity [30] which is required for tight junction [31, 32] and that oxyresveratrol improve tight junction integrity via MAPK pathways [33]. In this study, we addressed other three components of $C$. tricuspidata that also increase tight junction integrity. We speculate that the underlying mechanism of the enhancement of tight junction by the three components would be similar with oxyresveratrol due to their structures, phenolic compounds; nonetheless, it will be necessary to further investigate the mechanism of the three compounds on tight junction enhancement. Several papers showed that the three compounds could induce the generation of ROS that could damage cells and alter gene expression [34-36]. We confirmed that the three active compounds did not show significant cytotoxicity on $\mathrm{HaCaT}$ cells (data not shown); however, it still needs to be investigated the gene expression profile by the treatment of the compounds. We, currently, investigate the effect of the three compounds on cell signal pathway whose action might be result in the 
increase of claudin 1 and tight junction capacity. All together, we found that WECT could increase claudin 1 expression by which its representative components have synergetic effect on increase of claudin 1 expression.

Loss of claudin 1 in tight junctions can cause dehydration of the skin, leading to several skin diseases. Previous reports shown that by simply increase claudin 1 expression, it could alleviate the symptoms of those skin diseases. In the present study, we identified a novel regulatory effect of C. tricuspidata leaf extracts on claudin 1 expression and tight junction capacity. Our data suggest that WECT and its components could be used as a valuable treatment for preventing or improving tight junction-mediated skin diseases like dehydration and atopic dermatitis of the skin and as an additive for functional food or cosmetic for skin care.

\section{Authors' contributions}

Conceived and designed the experiments: EMK, KSP, MSN, KKK. Performed the experiments: JK, NC, EMK, KSP, YWK. Analyzed the data: JK, NC. Contributed plants materials: JHN. Wrote the paper: JK, NC, KKK. All authors read and approved the final manuscript.

\section{Funding}

This research was supported by Chungnam National University (2019-2020).

\section{Availability of data and materials}

The datasets used and analyzed in this study are available from the corresponding authors on reasonable request.

\section{Competing interests}

The authors declare that they have no competing interests.

\section{Author details}

${ }^{1}$ Department of Biochemistry, College of Natural Sciences, Chungnam National University, Daejeon 34134, Republic of Korea. ${ }^{2}$ Department of Predictive Toxicology, Korea Institute of Toxicology, Daejeon 34114 , Republic of Korea. ${ }^{3}$ Korea Institute of Oriental Medicine, Daejeon 34054, Republic of Korea. ${ }^{4}$ Division of Animal Resource Science, Chungnam National University, Daejeon 34134, Republic of Korea.

Received: 1 February 2020 Accepted: 26 April 2020

Published online: 09 May 2020

\section{References}

1. Hano Y, Matsumoto Y, Sun JY, Nomura T (1990) Structures of three new isoprenylated xanthones, cudraxanthones e, $\mathrm{f}$, and g 1,2. Planta Med 56(4):399-402

2. An RB, Sohn DH, Kim YC (2006) Hepatoprotective compounds of the roots of Cudrania tricuspidata on tacrine-induced cytotoxicity in Hep G2 cells. Biol Pharm Bull 29(4):838-840

3. Seo WG, Pae HO, Oh GS, Chai KY, Yun YG, Chung HT, Jang KK, Kwon TO (2001) Ethyl acetate extract of the stem bark of Cudrania tricuspidata induces apoptosis in human leukemia HL-60 cells. Am J Chin Med 29(2):313-320

4. Lee H, Ha H, Lee JK, Seo CS, Lee NH, Jung DY, Park SJ, Shin HK (2012) The fruits of Cudrania tricuspidata suppress development of atopic dermatitis in NC/Nga mice. Phytother Res 26(4):594-599

5. Bajpai VK, Sharma A, Baek KH (2013) Antibacterial mode of action of Cudrania tricuspidata fruit essential oil, affecting membrane permeability and surface characteristics of food-borne pathogens. Food Control 32(2):582-590
6. Jeon SM, Lee DS, Jeong GS (2016) Cudraticusxanthone A isolated from the roots of Cudrania tricuspidata inhibits metastasis and induces apoptosis in breast cancer cells. J Ethnopharmacol 194:57-62

7. Yoon CS, Kim DC, Quang TH, Seo J, Kang DG, Lee HS, Oh H, Kim YC (2016) A prenylated xanthone, Cudratricusxanthone A, isolated from Cudrania tricuspidata Inhibits lipopolysaccharide-induced neuroinflammation through Inhibition of NF-B and p38 MAPK Pathways in BV2 Microglia. Molecules 21(9):1240

8. Jo YH, Kim SB, Liu Q, Do SG, Hwang BY, Lee MK (2017) Comparison of pancreatic lipase inhibitory isoflavonoids from unripe and ripe fruits of Cudrania tricuspidata. PLoS ONE 12(3):e0172069

9. Jiang X, Cao C, Sun W, Chen Z, Li X, Nahar L, Sarker SD, Georgiev MI, Bai W (2019) Scandenolone from Cudrania tricuspidata fruit extract suppresses the viability of breast cancer cells (MCF-7) in vitro and in vivo. Food Chem Toxicol 126:56-66

10. Diamond JM (1977) Twenty-first Bowditch lecture. The epithelial junction: bridge, gate, and fence. Physiologist 20(1):10-18

11. Gonzalez-Mariscal L, Betanzos A, Nava P, Jaramillo BE (2003) Tight junction proteins. Prog Biophys Mol Bio 81 (1):1-44

12. Bazzoni G, Martinez-Estrada OM, Orsenigo F, Cordenonsi M, Citi S, Dejana E (2000) Interaction of junctional adhesion molecule with the tight junction components ZO-1, cingulin, and occludin. J Biol Chem 275(27):20520-20526

13. Ando-Akatsuka Y, Yonemura S, Itoh M, Furuse M, Tsukita S (1999) Differential behavior of E-cadherin and occludin in their colocalization with ZO-1 during the establishment of epithelial cell polarity. J Cell Physiol 179(2):115-125

14. Vermette D, Hu P, Canarie MF, Funaro M, Glover J, Pierce RW (2018) Tight junction structure, function, and assessment in the critically ill: a systematic review. Intensive Care Med Exp 6(1):37

15. Zorn-Kruppa M, Vidal YSS, Houdek P, Wladykowski E, Grzybowski S, Gruber R, Gorzelanny C, Harcup J, Schneider SW, Majumdar A et al (2018) Tight Junction barriers in human hair follicles-role of claudin-1. Sci Rep 8(1):12800

16. Sugawara T, Iwamoto N, Akashi M, Kojima T, Hisatsune J, Sugai M, Furuse M (2013) Tight junction dysfunction in the stratum granulosum leads to aberrant stratum corneum barrier function in claudin-1-deficient mice. J Dermatol Sci 70(1):12-18

17. Meertens L, Bertaux C, Cukierman L, Cormier E, Lavillette D, Cosset FL, Dragic T (2008) The tight junction proteins claudin-1,-6, and-9 are entry cofactors for hepatitis C virus. J Virol 82(7):3555-3560

18. Evans MJ, von Hahn T, Tscherne DM, Syder AJ, Panis M, Wolk B, Hatziioannou T, McKeating JA, Bieniasz PD, Rice CM (2007) Claudin-1 is a hepatitis $\mathrm{C}$ virus co-receptor required for a late step in entry. Nature 446(7137):801-805

19. De Benedetto A, Rafaels NM, McGirt LY, Ivanov Al, Georas SN, Cheadle C, Berger AE, Zhang K, Vidyasagar S, Yoshida T et al (2011) Tight junction defects in patients with atopic dermatitis. J Allergy Clin Immunol 127(3):773-786

20. Arabzadeh A, Troy TC, Turksen K (2007) Changes in the distribution pattern of Claudin tight junction proteins during the progression of mouse skin tumorigenesis. BMC Cancer 7:196

21. Verdier-Sevrain S, Bonte $F(2007)$ Skin hydration: a review on its molecular mechanisms. J Cosmet Dermatol 6(2):75-82

22. Kim YE, Cho N, Cheon S, Kim KK (2017) Bortezomib, a proteasome inhibitor, alleviates atopic dermatitis by increasing claudin 1 protein expression. Biochem Biophys Res Commun 493(1):744-750

23. Kim OK, Jun W, Lee J (2016) Effect of Cudrania tricuspidata and Kaempferol in endoplasmic reticulum stress-induced inflammation and hepatic insulin resistance in HepG2 cells. Nutrients 8(1):60

24. Lee Y, Oh J, Jeong YS (2015) Lactobacillus plantarum-mediated conversion of flavonoid glycosides into flavonols, quercetin, and kaempferol in Cudrania tricuspidata leaves. Food Sci Biotechnol 24(5):1817-1821

25. Jeong $\mathrm{CH}$, Choi GN, Kim JH, Kwak JH, Heo HJ, Shim KH, Cho BR, Bae YI, Choi JS (2009) In vitro antioxidative activities and phenolic composition of hot water extract from different parts of Cudrania tricuspidata. Prev Nutr Food Sci 14(4):283-289

26. Furuse M, Hata M, Furuse K, Yoshida Y, Haratake A, Sugitani Y, Noda T, Kubo A, Tsukita S (2002) Claudin-based tight junctions are crucial for the 
mammalian epidermal barrier: a lesson from claudin-1-deficient mice. J Cell Biol 156(6):1099-1111

27. Lee SS, Choi SK, Kim JW, Han HS, Kim KK (2019) Investigation of the effect of water extract from Cudrania tricuspidata fruit on tight junction in human keratinocyte. Kor J Herbol 34(1):8

28. Lee SB, Shin JS, Han HS, Lee HH, Park JC, Lee KT (2018) Kaempferol 7-O-beta-D-glucoside isolated from the leaves of Cudrania tricuspidata inhibits LPS-induced expression of pro-inflammatory mediators through inactivation of NF-kappaB, AP-1, and JAK-STAT in RAW 264.7 macrophages. Chem Biol Interact 284:101-111

29. Lee BW, Lee JH, Gal SW, Moon YH, Park KH (2006) Selective ABTS radicalscavenging activity of prenylated flavonoids from Cudrania tricuspidata. Biosci Biotechnol Biochem 70(2):427-432

30. Zheng ZP, Tan HY, Chen J, Wang MF (2013) Characterization of tyrosinase inhibitors in the twigs of Cudrania tricuspidata and their structure-activity relationship study. Fitoterapia 84:242-247

31. Dorfel MJ, Huber O (2012) Modulation of tight junction structure and function by kinases and phosphatases targeting occludin. J Biomed Biotechnol 2012:807356

32. Martin TA, Jiang WG (2009) Loss of tight junction barrier function and its role in cancer metastasis. Biochim Biophys Acta 1788(4):872-891
33. Jo H, Hwang D, Kim JK, Lim YH (2017) Oxyresveratrol improves tight junction integrity through the PKC and MAPK signaling pathways in Caco-2 cells. Food Chem Toxicol 108(Pt A):203-213

34. Hou N, Liu N, Han J, Yan Y, Li J (2017) Chlorogenic acid induces reactive oxygen species generation and inhibits the viability of human colon cancer cells. Anticancer Drugs 28(1):59-65

35. Kovacic P, Somanathan R (2018) Biological actions of natural phenolic antioxidants: reactive oxygen species and oxidative stress. Adv Biochem 10:2574-7258

36. Fonseca-Silva F, Inacio JD, Canto-Cavalheiro MM, Almeida-Amaral EE (2013) Reactive oxygen species production by quercetin causes the death of Leishmania amazonensis intracellular amastigotes. J Nat Prod 76(8):1505-1508

\section{Publisher's Note}

Springer Nature remains neutral with regard to jurisdictional claims in published maps and institutional affiliations.

\section{Submit your manuscript to a SpringerOpen ${ }^{\odot}$ journal and benefit from:}

- Convenient online submission

- Rigorous peer review

- Open access: articles freely available online

- High visibility within the field

- Retaining the copyright to your article

Submit your next manuscript at $\gg$ springeropen.com 